\title{
LEPIDOLITE WITH SIMULATED MATRIX
}

\author{
By John I. Koivula and C. W. Fryer
}

This article describes a crystal of gem-quality lepidolite (a lithium mica) with a simulated matrix. Under magnification, numerous gas bubbles were observed in the glue that was used to attach the crystal to the matrix. The main crystal was identified as lepidolite by means of X-ray diffraction.

The authors recently examined an unusual crystal in matrix (figure 1). The crystal specimen, which measured approximately $6.0 \mathrm{~cm} \times 1.7 \mathrm{~cm}$, reportedly came from Brazil. At first glance it looked very much like a fine pink tourmaline in matrix, complete with typical surface striations parallel to the length of the crystal. However, the specimen was much too lightweight to be tourmaline. It was obvious that a more detailed examination and some tests were needed to correctly identify the material.

\section{TESTING PROCEDURE}

The specimen was first examined carefully under the microscope. It was immediately apparent that the "matrix" was not natural, but had been glued to the crystal. As illustrated in figure 2, the "matrix" contained several areas of an epoxy-like glue in which gas bubbles were trapped. A thermal reaction test carried out on both the "matrix" and the crystal showed that the material simulating matrix was indeed glued on and that some of the glue had been smeared onto the surface of the main crystal, giving it a plastic-coated appearance in a number of areas. A slightly acrid odor and a small puff of white smoke were produced when the hot point was applied to the glue.

\section{ABOUT THE AUTHORS}

Mr. Koivula is senior gemologist, and Mr. Fryer is chief gemologist, at the Gemological Institute of America in Santa Monica, California

Acknowledgements: The authors would like to thank Loreen Haas of Crown Gems for the loan of the lepidolite specimen reported in this article.

(c) 1984 Gemological Institute of America 


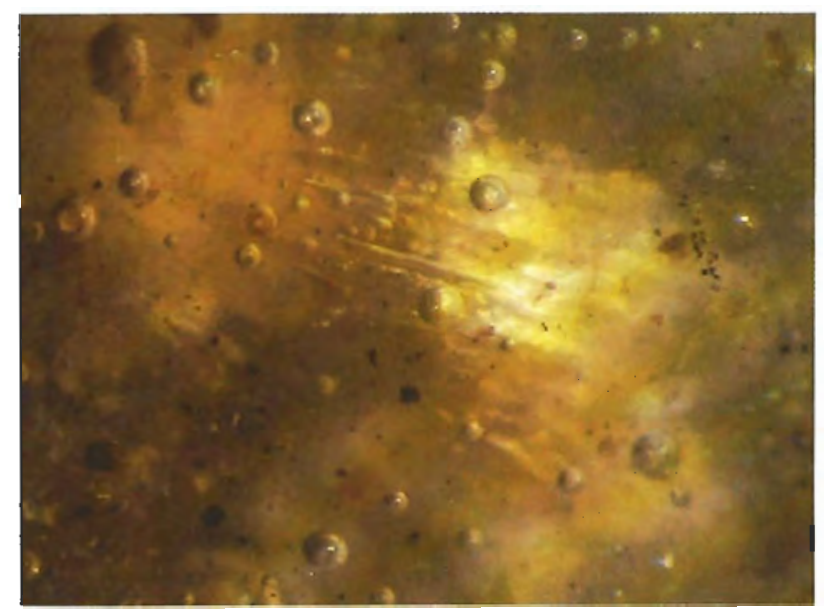

Figure 2. These gas bubbles trapped in the epoxy-like glue used to affix the matrix provided clear evidence that the specimen had been constructed. Oblique illumination, magnified $30 \times$

pink crystal did not show any signs of alluvial abrasion. Gross inconsistencies, to say the least.

Under. magnification, the natural-appearing surface striations running lengthwise on the crystal indicated a lamellar internal structure. There was no question now that the pink crystal was natural; it also appeared to be micaceous (figure 4).

Figure 3. This small green crystal fragment was attached to one end of the applied matrix. Unlike the "matrix," it showed few signs of abrasion. Magnified $6 \times$

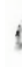

Since the large pinkish crystal was translucent, the specimen was checked with a spectroscope, polariscope, and dichroscope. No absorption spectrum was observed using a Beck spectroscope. The polariscope reaction was inconclusive, but the dichroscope showed definite lighter and darker shades of pink, proving the stone to be doubly refractive. During testing with ultraviolet radiation, only the glue reacted, fluorescing a pale whitish yellow. Because of the micaceous structure observed in the main pink crystal and the similarity of this specimen to a specimen of lepidolite that was pictured in a recent book (Sauer, 1982), lepidolite was next suspected.

We decided to use X-ray powder diffraction to conclusively identify the specimen. A spindle was prepared from a minute powder sample obtained from an inconspicuous area of the crystal. The

Figure 4. The micaceous habit of the lepidolite crystal is evident in this photomicrograph.

Magnified $6 \times$.

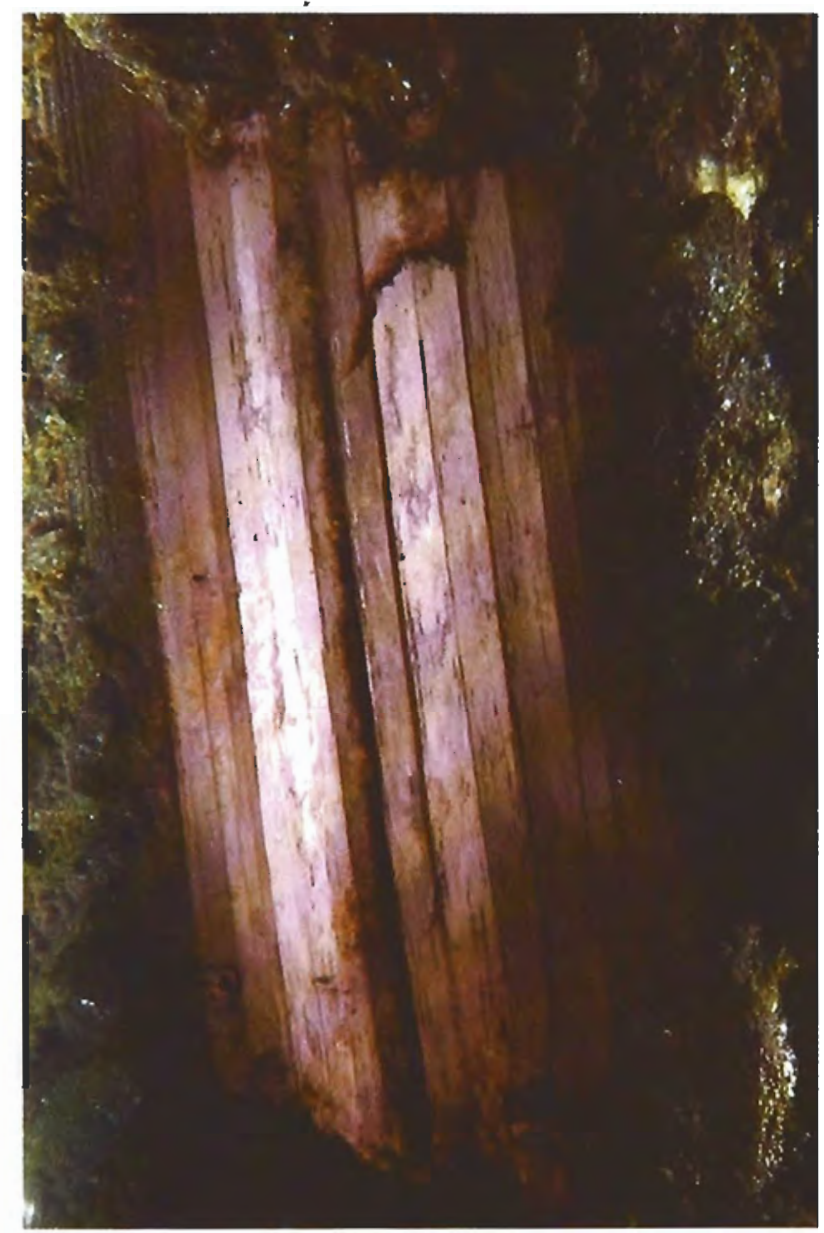


spindle was then mounted in a Debye-Scherrer powder camera and exposed for 4.2 hours to Xrays generated at $48 \mathrm{KV}$ and $18 \mathrm{MA}$ from a copper target tube. The pattern was measured for $\mathrm{d}$ spacing with a Nies overlay corrected for film shrinkage. The intensities of the lines were estimated visually. This pattern was then compared with five known lepidolite patterns. It matched the ASTM 14-11 pattern-a two-layered, monoclinic $\left(2 \mathrm{M}_{2}\right)$ structure-almost exactly.

\section{CONCLUSION}

Lepidolite cabochons are sometimes encountered by the jeweler, but a large, gemmy crystal such as this is quite rare. Although the crystal examined proved to be a beautiful example of gem-quality lepidolite, the matrix was not genuine. Just as gemologists must cope with synthetic, treated, and assembled gemstones, they must also sometimes deal with gem mineral specimens with simulated matrix, many of which are not as easy to identify as the one reported here. Some specimens may show virtually no evidence of assembly or alteration. In these cases, subtle signs such as inconsistencies in matrix texture or color are often useful clues. Readers interested in additional information are referred to an excellent paper on mineral chicanery written by Dunn, Bentley, and Wilson (1981).

\section{REFERENCES}

Dunn P.J., Bentley R.E., Wilson W.E. (1981) Mineral fakes. Minleralogical Record, Vol. 12, No. 4, pp. 197-220.

Sauer J.R. (1982) Brazil, Paradise of Gemstones. AGGS Industrias Gráficas S.A., Brazil.

The Gemological Institute of America wishes to extend its sincerest appreciation to all of the people who contributed to the activities of the Institute through donations of gemstones and other gemological materials. We are pleased to acknowledge many of you below:

Mr. and Mrs. Robert Anderson

*Mr. Mario Antolovich

Mr. Ben Ballinger

Mr. Craig Beagle

Mr. Jay B. Church

Mr. Frank Circelli

Mr. W. L. Cotton

Mr. Richard T. Daniels

Mr. Gene Dente

Ms. Sandra Dickson

Mr. Randy Disselkoen

Mr. Frank Faff

Dr. and Mrs, Joseph W. Farrar

Mr. and Mrs. Peter Flusser

Dr. Rodney B. Fruth

*Ms. Tula Funk

Mr. Robert E. Gaskell

Mr. Jeffrey Gendler

Dr. Samuel E. Gendler

Dr. Jaime Goldfarb
Mr. Michael P. Gouras

*Mr. Fred L. Gray

${ }^{*}$ Mr. Walter W. Greenbaum

Mr. Gary A. Griffith

Mr. Mack F. Guinn

Hammerman Brothers Inc.

Harper's Jewelry Inc.

Mr. Mark Herschede, Jr.

Mr. Eduardo Hertz

Mr. Bill Hines

Mr. Grant E. Hoffman

Mr. Nick Ijady

Mr. J. Clark Johnson

Mrs. S. V. Jones

Mr. Seiichi Kawai

Mr. Richard Larson

Mr. Douglas E. Lee

Mr. Jim Lestock

Ms. Betty H. Llewellyn

Mr. Thomas H. Looker
*Mr. Gerald May

Mr. Michael Menser

Mr. George G. Messersmith

Mr. Ronald K. Moore

Mr. William R. Moore

Ms. Julia Myers

Mr. John Ng

Judith Osmer, Ph.D.

*Mr. Ron Ringsrud

Mr. LaVerne W. Rees

Mr. Dean Sander

Ms. Jeanne Scher

Mr. Jacques Schupf

Dr. William Shadish

Mr. Irwin Shakin

Mr. Jerry Shroat

Mr. David B. Sigler

Mr. Ronald $H$. Tanaka

Mr. Alexander Yodice

*Denotes book donation to GIA Library. 